\title{
Effects of the stem extracts of Schisandra glaucescens Diels on collagen-induced arthritis in Balb/c mice
}

Yan Xiang ${ }^{1, \#}$, Tiantian Zhang, ${ }^{2, \#}$, Chunpin Yin ${ }^{2, \#}$, Jiewen Zhou ${ }^{2}$, Rong Huang ${ }^{3}$,Shasha $\mathrm{Gao}^{2}$, Lamei Zheng ${ }^{2}$, Xiaogang Wang ${ }^{2}$, Anne Manyande ${ }^{4}$, Xuebi Tian ${ }^{5}$, Jiachun Chen², Jinbo Fang ${ }^{2, *}$

1. Department of Ophthalmology, Tongji hospital, Tongji medical college, Huazhong University of Science and Technology, Wuhan 430030, Hubei, China

2.School of Pharmacy, Hubei Key Laboratory of Natural Medicinal Chemistry and Resource Evaluation, Tongji Medical College,Huazhong University of Science and Technology, Wuhan 430030 ,China

3. Department of Ophthalmology, Hubei Provincial Hospital of Traditional Chinese Medicine, Wuhan 430061, Hubei, China

4. School of Psychology, Social Work and Human Sciences, University of West London, London, UK

5. Department of Anesthesiology, Tongji hospital, Tongji medical college, Huazhong University of Science and Technology, Wuhan 430030, Hubei, China

\# Yan Xiang, Tiantian Zhang and Chunpin Yin have the equal contribution to this paper.

* Corresponding author:

Jinbo Fang, email: fangjb@hust.edu.cn. 
Schisandra glaucescens Diels (SGD) is used in a subclass of traditional Chinese medicine known as "Tujia drugs". It has been long used for the treatment of rheumatoid arthritis (RA), cough with dyspnea, spontaneous sweating, night sweating, chronic diarrhea, and neurasthenia.

\footnotetext{
Abstract

Aim of the study: To evaluate the antiarthritic activity of acetate (EA) and $n$-butanol (Bu)
} 
fractions of SGD extract on a collagen-induced arthritis mice model.

Materials and Methods: Acute toxicity of EA and Bu fractions of SGD extract was evaluated by gavage on normal mice. Pharmacological investigations were conducted on arthritis male $\mathrm{Balb} / \mathrm{c}$ mice. The animal model was induced by immunization with type II bovine collagen (CII) on the 1st and the 14th day of the experimental schedule. EA fraction (104, 312, 936 $\mathrm{mg} / \mathrm{kg}), \mathrm{Bu}$ fraction $(156,469,1407 \mathrm{mg} / \mathrm{kg})$ of SGD extract was orally administered every two days since the 15th day for 3 weeks. Progression of edema in the paws was measured using a vernier caliper every 3 days since the 10th day. At the end of the experiment, the spleen index and histological changes of the hind knee joints were investigated. Additionally, to explore the possible antirheumatic mechanisms of the EA and $\mathrm{Bu}$ fractions, ELISA was carried out to analyze TNF- $\alpha$, IL-10, IL-6 and IL- $1 \beta$ in the serum.

Results: The half lethal doses of both $\mathrm{EA}$ and $\mathrm{Bu}$ fractions were much higher than the dose administered in the pharmacological investigations. Oral administration of EA fraction and $\mathrm{Bu}$ fraction of SGD extract significantly and does-dependently inhibited type II collagen induced arthritis (CIA) in mice, as indicated by the effects on paws swelling and spleen index. Histopathological examinations demonstrated that SGD effectively protected the bones and cartilages of knee joints from erosion, lesion and deformation. Besides, the serum concentrations of cytokines TNF- $\alpha$, IL- $1 \beta$ and IL- 6 were significantly lower than the ones from the vehicle control group. Respectively, while cytokine IL-10 was remarkably higher compare with the vehicle control group.

Conclusions: SGD might be a safe and effective candidate for the treatment of RA, and deserves further investigation on the chemical components in both $\mathrm{EA}$ and $\mathrm{Bu}$ fractions of SGD extract.

Keywords: Schisandra glaucescens Diels, Rheumatoid arthritis, Collagen-induced arthritis (CIA), immunomodulation, inflammatory cytokines

\section{Introduction}

Rheumatoid arthritis (RA) is a chronic inflammatory and destructive joint disease that 
affects $0.5-1 \%$ of the population worldwide. It usually leads to severe disability and reduces the quality of life (Smolen and Steiner, 2003). Initially characterized by an inflammatory response of the synovial membrane with hyperplasia and inflammatory cells infiltration, RA is characterized as cartilage erosion and bone destruction. The aggressive pannus front invades and destroys local articular structures (Firestein, 2003). The cytokines establish a complex network whose balance depends on various pathways. Among them, pro-inflammatory cytokines such as tumor necrosis factor alpha (TNF- $\alpha$ ), interleukin-1 beta (IL-1 $\beta$ ) and interleukin-6 (IL-6), as well as immunoregulatory cytokines such as interleukin-10 (IL-10), have been shown to play key roles in pathological mechanism in RA (Hueber and McInnes, 2007). Particularly, IL-1 $\beta$ was found to be the main mediator of cartilage and bone destruction (Joosten et al., 1999).

Drugs for RA treatment can roughly be divided into three classes: non-steroidal antiinflammatory drugs (NSAIDs), disease-modifying antirheumatic drugs (DMARDs) and herbal medicines. NSAIDs only interfere with a small segment of the inflammatory cascade, namely prostaglandin generation by cyclooxygenases, but does not postpone the underlying immunoinflammatory events or retard joint destruction (Smolen and Steiner, 2003). Traditional DMARDs (such as methotrexate, hydroxychloroquine and sulfasalazine) and biological DMARDs (such as tumor necrosis factor antagonists and inerleukin-1 antagonist) have been reported to have severe side effects and may lose their treatment effect after prolonged use (Maini et al., 1999; Silverstein et al., 2000; Simon, 2000). Herbal medicines with biological activities have been widely used to treat bone diseases for thousands of years, and will undoubtedly continue to be used as cost-effective alternatives of commercial pharmaceutical products. Recently, the therapeutic effect of several traditional herbal medicines on collageninduced arthritis has been studied (Chen et al., 2011; Jung et al., 2012; Liu et al., 2012).

Schisandra glaucescens Diels (SGD) is a woody liana and used as a folk medicine for a long history. The stems of SGD, locally called "Huaxueteng" or "Xiangxueteng", is used in both "Tujia drugs" and "Miao drugs" (Xiong et al., 2004; Wan et al., 1990). It has favorable therapeutic effects on rheumatoid arthritis, trauma pain and goiter by Chinese medicine practices Jianfu or medicated wine (Chinese Materia Midica, 1999). For its long history and effective to be used as a folk herbal medicine, several studies had already reported that some new bioactive compounds found from this plant, such as lignans with antioxidant and neuroprotective properties, cycloartane triterpenoids with effect against FXR and 
estrogen receptor modulators(Yu et al, 2014;Cao et al, 2013; Yu et al, 2012, Zou et al, 2012). However, to best our knowledge, its therapeutic effect and its possible bioactive compound on RA has not been carefullly investigated in modern ways. Its pharmacological mechanism remains unclear.

Collagen-induced arthritis (CIA) is an experimental autoimmune disease model, which can be elicited in susceptible strains of rodents (rat and mouse) by immunization with type II bovine collagen (CII), the major protein constituenof articular cartilage (Rosloniec et al., 2010).

It resembles RA in many ways, from genetic linkage to pathology and clinic manifestations (Myers et al., 1997). Additionally, among the antigen-defined, cartilage-protein based models, it has the shortest duration between immunization and disease manifestation (Brand et al., 2007). Thus the CIA model is the most widely used one to address questions concerning the disease pathogenesis and to elucidate the rationale for a therapy. In the present study, we evaluated the therapeutic effects of extract of SGD stem on CIA in Balb/c mice.

\section{Materials and Methods}

\subsection{Animals}

Male Balb/c mice, aged 6 weeks, (obtained from the Experimental Animal Center, Tongji Medical College, Huazhong University of Science and Technology, China) were maintained on a 14/10 hour light/dark cycle (light on 5:00 AM - 7:00 PM: a standard light/dark schedule that is used by the university animal care facility) with food and water provided ad libitum before initiation of experimental procedures. The mice were housed under standard laboratory conditions at an ambient temperature of $22 \pm 3$ with humidity of $60 \pm 5 \%$. All animals were handled according to the Guide for the Care and Use of Laboratory Animals published by the US National Institute of Health (NIH Publication No. 85 - 23, revised in 1996) and received humane care. The experimental rotocols were approved by Huazhong University of Science and Technology Committee on Animal Care and Use.

\subsection{Preparation of the extracts and fractions}

The stems of Schisandra glaucescens Diels were collected from Enshi, Hubei Province, People's Republic of China, in July 2007, and identified by Prof. Dingrong Wan at School of

Pharmacy, South-Central University for Nationalities (China). A voucher specimen (SGD20070805) has been deposited in the Pharmacognosy Laboratory of School of Pharmacy, Tongji Medical College of Huazhong University of Science and Technology, Wuhan, China. 
The dry stems of SGD $(10 \mathrm{~kg})$ were powdered and extracted with $95 \% \mathrm{EtOH}$ under reflux ( $6 \mathrm{~h} \times 3$ times). The combined solution was filtered and evaporated to dryness using a rotary evaporator (SENCO, Shanghai, China) under reduced pressure. The extract was then suspended in water and successively partitioned with ethyl acetate (EA) and $n$-butanol $(\mathrm{Bu})$. The EA fraction and Bu fraction were dried with a vacuum dryer to obtain the EA ( $260 \mathrm{~g})$ and $\mathrm{Bu}(391 \mathrm{~g})$ fractions. The $\mathrm{w} / \mathrm{w}$ extraction yields for the EA and $\mathrm{Bu}$ fractions of the dried SGD were $2.6 \%$ and $3.91 \%$ respectively. The fractions were kept at $4{ }^{\circ} \mathrm{C}$.

The standardization of SGD EA and Bu fractions can be seen in Supplementary Material.

\subsection{Acute oral toxicity study}

To evaluate the acute oral toxicity of EA and $\mathrm{Bu}$ fractions, 15 male and 15 female mice randomly assigned to 3 experimental groups and the method referring to a description by Walum (1998) was used. The single-dose toxicity of EA fraction and $\mathrm{Bu}$ fraction were investigated at the dose of $4.6 \mathrm{~g} / \mathrm{kg}$ and $7.82 \mathrm{~g} / \mathrm{kg}$ body weight, respectively, both equal to 200 $\mathrm{g}$ dry stems per kilogram body weight. The dose was the maximum feasible dose (refer to Diehl KH et al, 2001, J. Appl. Toxicol. 21, 15-23) that we could take: administration volumes considered good practice $(0.1 \mathrm{ml} / 10 \mathrm{~g}$ mouse refer to Diehl KH et al, 2001, J. Appl. Toxicol. 21, 15-23) and the highest solubility of both compounds in the $0.5 \%$ Caboxy Methyl Cellulose (CMC-Na) solution. The control group was orally treated with $0.5 \%$ CMC-Na. Mortality, body weight and general behaviors were monitored during 14 days.

\subsection{Induction of CIA and drug administration}

For a more detailed explanation on how to induce CIA, refer to a protocol by Brand et al., (2007). Briefly, the normal group consisting of 10 mice was randomly assigned before the experiment without immunization, while the model and treatment groups were immunized as follows. Bovine type II collagen (Chondrex, USA) was dissolved in $0.1 \mathrm{M}$ acetic acid at a concentration of $2 \mathrm{mg} / \mathrm{ml}$ and kept at 4 overnight, and then it was emulsified with an equal volume of Freund's complete adjuvant (CFA) (Sigma, USA) to a final CII concentration of 1 $\mathrm{mg} / \mathrm{ml}$. On the 1 st day of the experiment, all mice were intradermally injected at several sites at the base of the tail with the CII emulsion, with $0.1 \mathrm{ml}$ per mice, as the primary immunization. Two weeks after the primary immunization (on the 14th day), the mice were challenged again by injecting the same volume of CII emulsion at the same location.

Testing mice were randomly divided into 10 groups ( $\mathrm{n}=10$ per group) and defined as following: Normal group as negative control for CIA, model group as positive control for 
disease induced, of other 8 tested groups, two groups as positive treatment control and treated with dexamethasone(Dex) or Tripterygium glycosides (TGs) respectively, 3 groups treated with different dose of stem extraction from EA fraction and 3 groups treated with different dose of stem extraction from $\mathrm{Bu}$ fraction. The normal group was orally treated with distilled water containing $0.5 \% \mathrm{CMC}-\mathrm{Na}(0.1 \mathrm{ml} / 10 \mathrm{~g}$ body weight $)$. Dex treatment groups were treated orally with dexamethasone (Dex) (3 mg/kg body weight) (Earp et al., 2008; Kang et al., 2000) and corresponding for TGs treatment group was TGs $(60 \mathrm{mg} / \mathrm{kg}$ body weight) (Wan et al., 2013). Each fraction was administered at three doses according to the conversion tables of dose relationship between humans and mice (Shaw et al., 2008). Specifically, the doses were 140,312 and $936 \mathrm{mg} / \mathrm{kg}$ for EA fraction and 156, 469 and $1407 \mathrm{mg} / \mathrm{kg}$ for Bu fraction in mice, which were equivalent to 4,12 and $36 \mathrm{~g}$ dried stems per every kilo of human body weight. All groups were administered orally with vehicle, Dex, TGs, EA or Bu fractions once every 2 days beginning on the 15th day for 3 weeks (time schedule detailed in Fig.1).

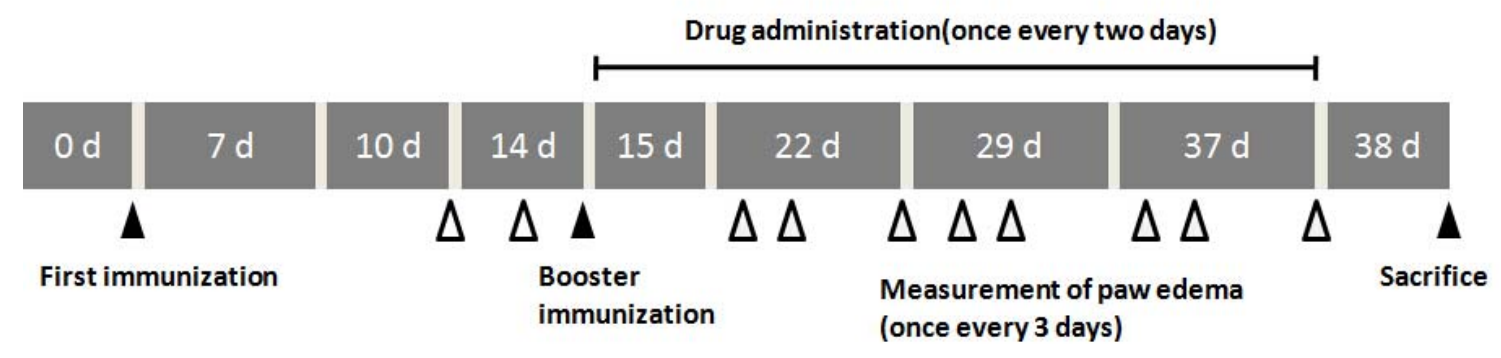

Fig.1. Chart for experimental design

\subsection{Measurement of paw edema progression}

From the 10th day following the primary immunization, the thickness of the right hind paw was measured every 3 days with a Vernier calliper (GBT1214-1986, Shanghai) by an independent operator without prior knowledge of the experimental groups. Each paw was measured three times on each day, and the average was calculated as the final value as an indicator of the progression of CIA.

\subsection{Measurement of spleen index}

At the end of the experiment, all mice were sacrificed by cervical dislocation after serum sample collection. Their spleens were weighed immediately after dissection. The spleen indexes were calculated referring to Zhang's study (Zhang et al, 2004), by using the following formula: Spleen Index = Spleen weight / Body weight. 


\subsection{Analysis of histopathology}

For histological analysis of knee joints, the right hind limbs of mice were removed postmortem and fixed in $4 \%$ paraformaldehyde for $24 \mathrm{~h}$, decalcified with $12.5 \%$ ethylene diamine tetraacetic acid (EDTA, pH 7.0) for 15 days, embedded in paraffin, and then sectioned at the sickness of 6-8 $\mu \mathrm{m}$ thickness. Tissue sections were stained with hematoxylin and eosin prior to observation by light microscopy (Leica, DM2500, Germany). Infiltration of inflammatory cells, proliferation of synoviocyte, pannus formation, joint space change, cartilage hyperplasia and/or erosion, and bone destruction were blindly graded by a pathologist and assigned scores between 0-3 based on the following criteria: 0 , no changes; 1, mild changes; 2, moderate changes; 3, severe changes (Seeuws et al., 2010).

\subsection{Detection of serum cytokine level by ELISA}

The levels of TNF- $\alpha$, IL-1 $\beta$, IL-6 and IL-10 in serum samples were measured by commercially available enzyme-linked immunosorbent assay kits (ELISA) following the standard kit protocol. The kits and the type of ELISA used for the study were Mouse TNFalpha Quantikine ELISA Kits (R\&D Systems Inc., USA), Mouse IL-1 beta Quantikine ELISA Kits (R\&D Systems Inc., USA), Mouse IL-6 Quantikine ELISA Kits (R\&D Systems Inc., USA), and Mouse IL-10 Quantikine ELISA Kits (R\&D Systems Inc., USA). The concentrations of these cytokines were calculated from the respective standard curves.

2.10. Statistical analysis

All data analysis was completed using the Graphpad PRISM version 5.0 software and IBM SPSS Statistics 19 software. Data are expressed as mean $\pm \mathrm{SEM}$. All neurochemical data were analyzed by one way analysis of variance (ANOVA) followed by Tukey's post hoc analysis. Histopathological score data were analyzed by Kruskal-Wallis $\mathrm{H}$ test followed by Nemenyi test. $P$ values lower than 0.05 were considered statistically significant.

\section{Results}

\subsection{Acute oral toxicity of EA and Bu fractions of SGD extract}

To test the acute toxicity of EA and $\mathrm{Bu}$ fractions from SGD, an extremely high dose was administered to normal mice by gavage. The mortality, body weight and general behaviors were monitored for 14 days. No mice died after gavage administration of EA and Bu fractions. For this reason, we did not get the half lethal dose for either EA or Bu fraction. When comparing normal mice with those were received $\mathrm{Bu}(7.82 \mathrm{~g} / \mathrm{kg})$ or EA $(4.6 \mathrm{~g} / \mathrm{kg})$ administration, there was no significant difference in activity and general behaviors for both 
males and females. These results suggest that the $\mathrm{Bu}$ fraction of SGD extract were not toxic in vivo at the studied dose. The half lethal doses of both $\mathrm{EA}$ and $\mathrm{Bu}$ fractions are much higher than the doses we investigated in activity tests. Thus both EA and Bu fractions of SGD extract could be safely used in the following study.

\subsection{SGD extracts reduced collagen-induced arthritis on mice}

The changes of paw thickness from the 10th to the 34th day are displayed in Table 1. As expected, the hind paws of the CIA model mice significantly swelled from day 19 to the end of the experiment compared with normal mice (all $P<0.01$ ). Compared with the CIA model group, the paw swelling of EA $(104 \mathrm{mg} / \mathrm{kg})$ treated group was significantly ameliorated from day 25 (all $P<0.01)$, the pawing swelling of EA $(312 \mathrm{mg} / \mathrm{kg}$ ) treated group was inhibited from day 22 (all $P<0.01)$, and the paw swelling of EA $(936 \mathrm{mg} / \mathrm{kg}$ ) treated group was ameliorated from day 19 (all $P<0.01$ ). For Bu $(156,469,1407 \mathrm{mg} / \mathrm{kg}$ ) treated groups, paw swelling was significantly reduced respectively on days 25, 22 and 19, respectively, compared with the CIA model group (all $P<0.01$ ). Importantly, the edema inhibition effect of EA (936 $\mathrm{mg} / \mathrm{kg})$ and $\mathrm{Bu}(1407 \mathrm{mg} / \mathrm{kg})$ occurred earlier than TGs $(60 \mathrm{mg} / \mathrm{kg})$.

The increased spleen index in RA disease reflects an enlarged spleen. The spleen index of the CIA model mice significantly increased compared with normal mice $(P<0.01)$. However, spleen indexes of CIA mice treated with SGD were suppressed when compared with the model group (Fig.2). Compared with the model group, groups treated with EA (936 $\mathrm{mg} / \mathrm{kg})$ and $\mathrm{Bu}(156,469,1407 \mathrm{mg} / \mathrm{kg})$ displayed significantly decreased spleen index $(P<$ 0.01). EA (312 mg/kg) also showed decreased spleen index compared with CIA model group $(P<0.05)$. 


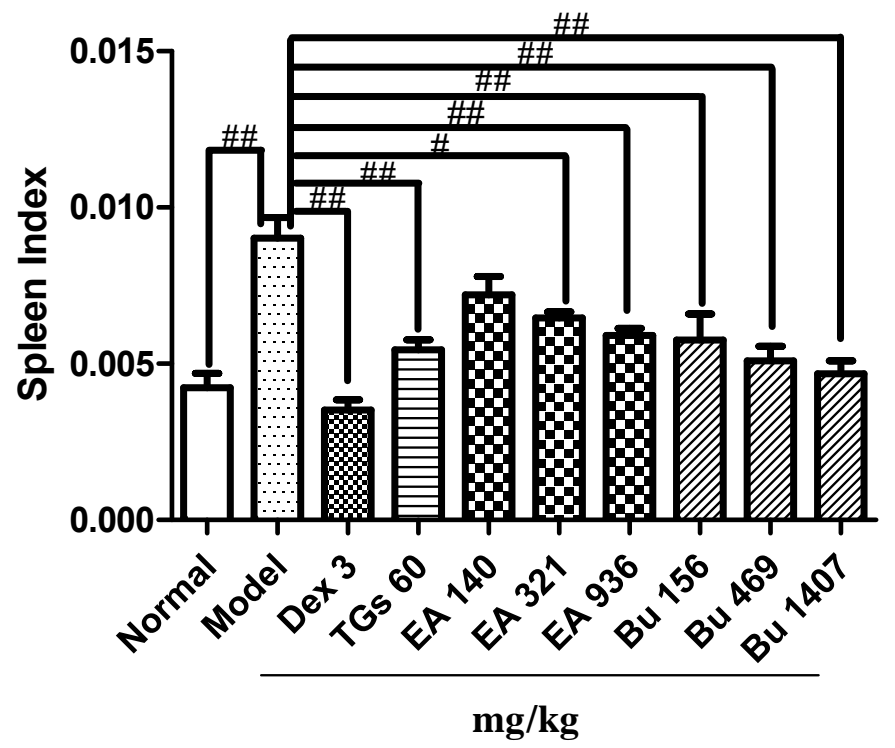

Fig.2. Effects of SGD on the spleen indexes on CIA mice. Data were analyzed by one-way ANOVA followed by Tukey's post hoc analysis. Values represent mean \pm SEM $(n=10)$, \#P<0.05, \#\# $P<0.01$ compared with the model group. Model male Balb/c mice only received $0.5 \% \mathrm{CMC}-\mathrm{Na}$ orally. 
Table 1

Effects of ethyl acetate and $n$-butanol fractions of Schisandra glaucescens Diels extract on hind paw swelling in CIA mice

\begin{tabular}{cccccccccc}
\hline \multirow{2}{*}{$\begin{array}{c}\text { Groups } \\
\text { (mg/kg) }\end{array}$} & \multicolumn{7}{c}{ The changes of hind paw swelling (cm) } \\
\cline { 2 - 9 } & Day10 & Day13 & Day16 & Day19 & Day22 & Day25 & Day28 & Day31 & Day34 \\
\hline Normal & $0.218 \pm 0.003$ & $0.219 \pm 0.004$ & $0.221 \pm 0.004$ & $0.224 \pm 0.003 \# \#$ & $0.226 \pm 0.002 \# \#$ & $0.226 \pm 0.002 \# \#$ & $0.221 \pm 0.004 \# \#$ & $0.223 \pm 0.002 \# \#$ & $0.226 \pm 0.003 \# \#$ \\
Model & $0.228 \pm 0.003$ & $0.235 \pm 0.004$ & $0.244 \pm 0.004$ & $0.252 \pm 0.003$ & $0.261 \pm 0.004$ & $0.266 \pm 0.002$ & $0.266 \pm 0.003$ & $0.268 \pm 0.002$ & $0.265 \pm 0.002$ \\
Dex (3) & $0.227 \pm 0.004$ & $0.226 \pm 0.004$ & $0.222 \pm 0.004 \# \#$ & $0.217 \pm 0.004 \# \#$ & $0.220 \pm 0.004 \# \#$ & $0.217 \pm 0.004 \# \#$ & $0.214 \pm 0.004 \# \#$ & $0.217 \pm 0.004 \# \#$ & $0.217 \pm 0.003 \# \#$ \\
TGs (60) & $0.232 \pm 0.003$ & $0.232 \pm 0.003$ & $0.244 \pm 0.005$ & $0.230 \pm 0.005 \#$ & $0.230 \pm 0.008 \# \#$ & $0.238 \pm 0.004 \# \#$ & $0.251 \pm 0.006 \# \#$ & $0.232 \pm 0.005 \# \#$ & $0.230 \pm 0.003 \# \#$ \\
EA (104) & $0.230 \pm 0.003$ & $0.235 \pm 0.004$ & $0.238 \pm 0.003$ & $0.236 \pm 0.004$ & $0.238 \pm 0.003 \#$ & $0.239 \pm 0.007 \# \#$ & $0.235 \pm 0.004 \# \#$ & $0.239 \pm 0.005 \# \#$ & $0.240 \pm 0.004 \# \#$ \\
EA (312) & $0.227 \pm 0.003$ & $0.231 \pm 0.004$ & $0.233 \pm 0.004$ & $0.235 \pm 0.004$ & $0.232 \pm 0.006 \# \#$ & $0.229 \pm 0.007 \# \#$ & $0.228 \pm 0.004 \# \#$ & $0.227 \pm 0.004 \# \#$ & $0.229 \pm 0.006 \# \#$ \\
EA (936) & $0.227 \pm 0.005$ & $0.236 \pm 0.005$ & $0.241 \pm 0.004$ & $0.228 \pm 0.005 \# \#$ & $0.230 \pm 0.005 \# \#$ & $0.222 \pm 0.005 \# \#$ & $0.225 \pm 0.004 \# \#$ & $0.229 \pm 0.002 \# \#$ & $0.221 \pm 0.002 \# \#$ \\
Bu (156) & $0.227 \pm 0.002$ & $0.228 \pm 0.002$ & $0.239 \pm 0.003$ & $0.238 \pm 0.005$ & $0.241 \pm 0.006$ & $0.225 \pm 0.007 \# \#$ & $0.236 \pm 0.005 \# \#$ & $0.236 \pm 0.005 \# \#$ & $0.233 \pm 0.003 \# \#$ \\
Bu (469) & $0.226 \pm 0.004$ & $0.229 \pm 0.004$ & $0.237 \pm 0.004$ & $0.229 \pm 0.004 \#$ & $0.227 \pm 0.005 \# \#$ & $0.220 \pm 0.004 \# \#$ & $0.228 \pm 0.004 \# \#$ & $0.229 \pm 0.004 \# \#$ & $0.224 \pm 0.004 \# \#$ \\
Bu (1407) & $0.229 \pm 0.002$ & $0.233 \pm 0.003$ & $0.235 \pm 0.003$ & $0.226 \pm 0.004 \# \#$ & $0.227 \pm 0.004 \# \#$ & $0.218 \pm 0.005 \# \#$ & $0.221 \pm 0.002 \# \#$ & $0.225 \pm 0.002 \# \#$ & $0.223 \pm 0.003 \# \#$ \\
\hline
\end{tabular}

Data were analyzed by one-way ANOVA followed by Tukey's post hoc analysis. Values represent mean \pm SEM (n=10).

\# $P<0.05$, \#\# $P<0.01$ compared with model group 
To determine whether SGD prevented articular destruction, hind knee joints of CIA mice were investigated by histological examination (Figs.3-6). Non-immunized mice showed normal articular cartilage, absence of infiltrate in the synovium and open joint space (Fig. 3A). As shown in Fig. 3B, the knee joints of induced arthritis model showed typical pathological changes with inflammatory cell infiltration, various degrees of hyperplastic synovium, formation of pannus, cartilage hyperplasia and erosion, and severely narrow joint space. Groups treated with EA $(936 \mathrm{mg} / \mathrm{kg})$ and $\mathrm{Bu}(1407 \mathrm{mg} / \mathrm{kg})$ had considerably reduced signs of disease severity (Figs. 5G and 6J). A small increase in synovial cell infiltration and/or cartilage hyperplasia were detected in the joints of mice receiving EA (312 mg/kg) and Bu (469 mg/kg), but little or no discernable pannus formation and cartilage erosion were observed in the knee joints (Figs. 5F and 6I). Moderate inflammatory cell infiltration, slight pannus formation and hyperplasia synovium were seen in the joints of animals treated with EA $(140 \mathrm{mg} / \mathrm{kg})$ and $\mathrm{Bu}$ $(156 \mathrm{mg} / \mathrm{kg})$ (Figs. 5E and 6H).

To evaluate and quantify the severity of histological changes, a score system described before (Seeuws et al., 2010) was used. As shown in Table 2, the pathological score of the model group was significantly higher than the normal group $(P<0.01)$. EA $(312,936 \mathrm{mg} / \mathrm{kg})$ treated groups showed obvious changes (all $P<0.05)$. Meanwhile, $\mathrm{Bu}(469,1407 \mathrm{mg} / \mathrm{kg}$ ) fraction was effective in preventing destruction of joint (all $P<0.05$ ).

These results indicate that both EA and Bu fractions from SGD successfully slowed down the development of collagen induced arthritis in mice.

Table 2

Effects of SGD on histopathological score in CIA mice

\begin{tabular}{|c|c|c|c|c|c|}
\hline \multirow{2}{*}{$\begin{array}{l}\text { Groups } \\
(\mathrm{mg} / \mathrm{kg})\end{array}$} & \multicolumn{4}{|c|}{ Number of mice in each histopathological score } & \multirow{2}{*}{$\begin{array}{l}P \text { values (compared } \\
\text { with model group) }\end{array}$} \\
\hline & 0 & 1 & 2 & 3 & \\
\hline Normal & 9 & 1 & 0 & 0 & 0.001 \\
\hline Model & 0 & 0 & 3 & 7 & - \\
\hline Dex (3) & 4 & 5 & 1 & 0 & 0.029 \\
\hline TGs (60) & 5 & 5 & 0 & 0 & 0.016 \\
\hline EA (104) & 0 & 3 & 2 & 5 & 0.097 \\
\hline EA (312) & 1 & 6 & 3 & 0 & 0.037 \\
\hline EA (936) & 4 & 4 & 2 & 0 & 0.029 \\
\hline $\mathrm{Bu}(156)$ & 0 & 3 & 6 & 1 & 0.072 \\
\hline $\mathrm{Bu}(469)$ & 1 & 6 & 3 & 0 & 0.029 \\
\hline $\mathrm{Bu}(1407)$ & 6 & 4 & 0 & 0 & 0.029 \\
\hline
\end{tabular}

Data were analyzed by Kruskal-Wallis $H$ test followed by Nemenyi test. Histopathological scores: 0 , no changes; 1 , mild changes; 2 , moderate changes; 3 , severe changes. There's significant difference between groups. 

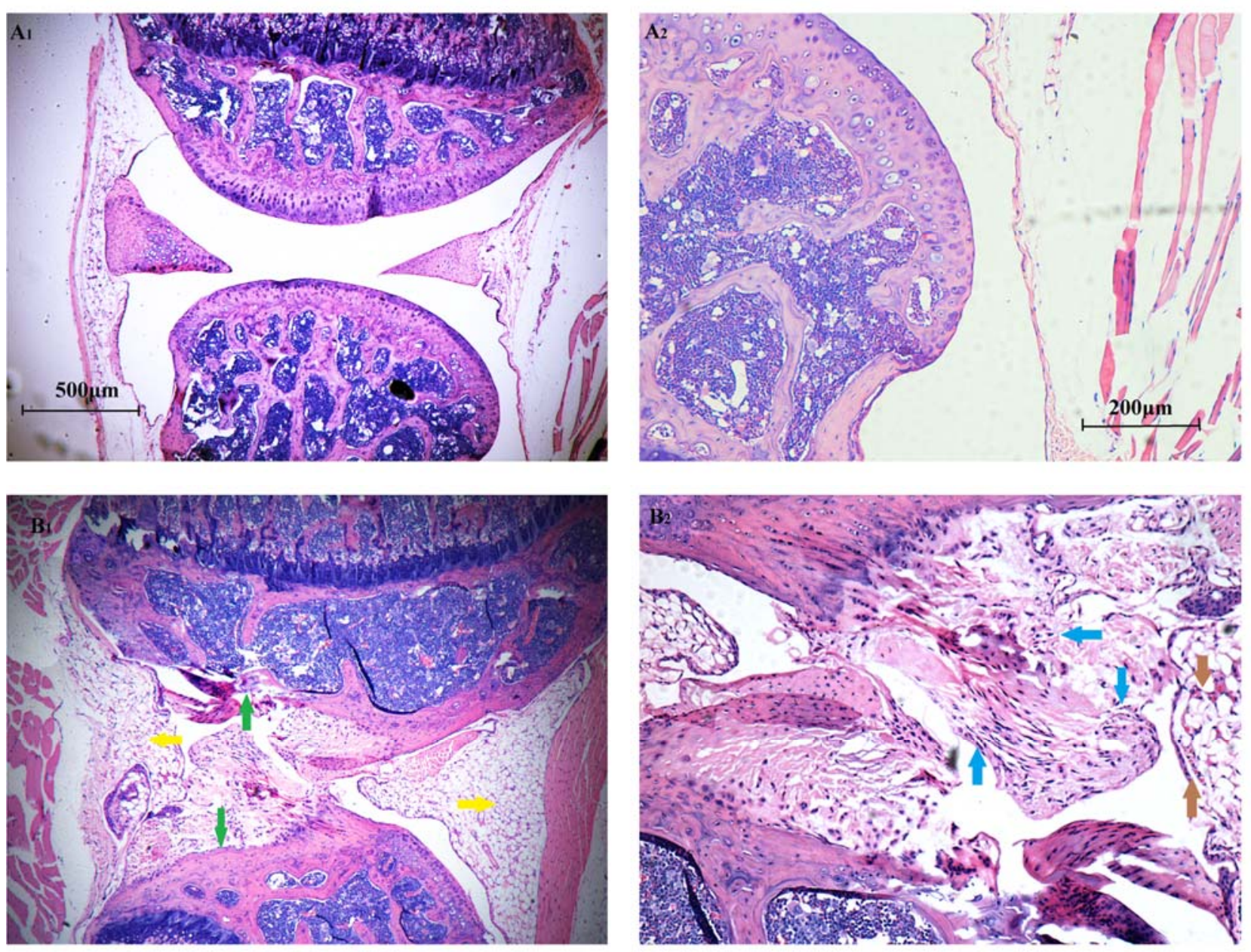

Fig.3. Histology changes of joints from the normal group and the model group mice: (A) Normal group mice showed the normal articular cartilage, absence of damage in the synovium and open joint space; (B) Model group mice showed marked infiltration of inflammatory cells and synovial hyperplasia. $\longrightarrow$, cartilage hyperplasy and erosion; $\rightarrow$, synovia hyperplasia; $\Rightarrow$, inflammatory cell infiltration; $\Rightarrow$, pannus formation. 

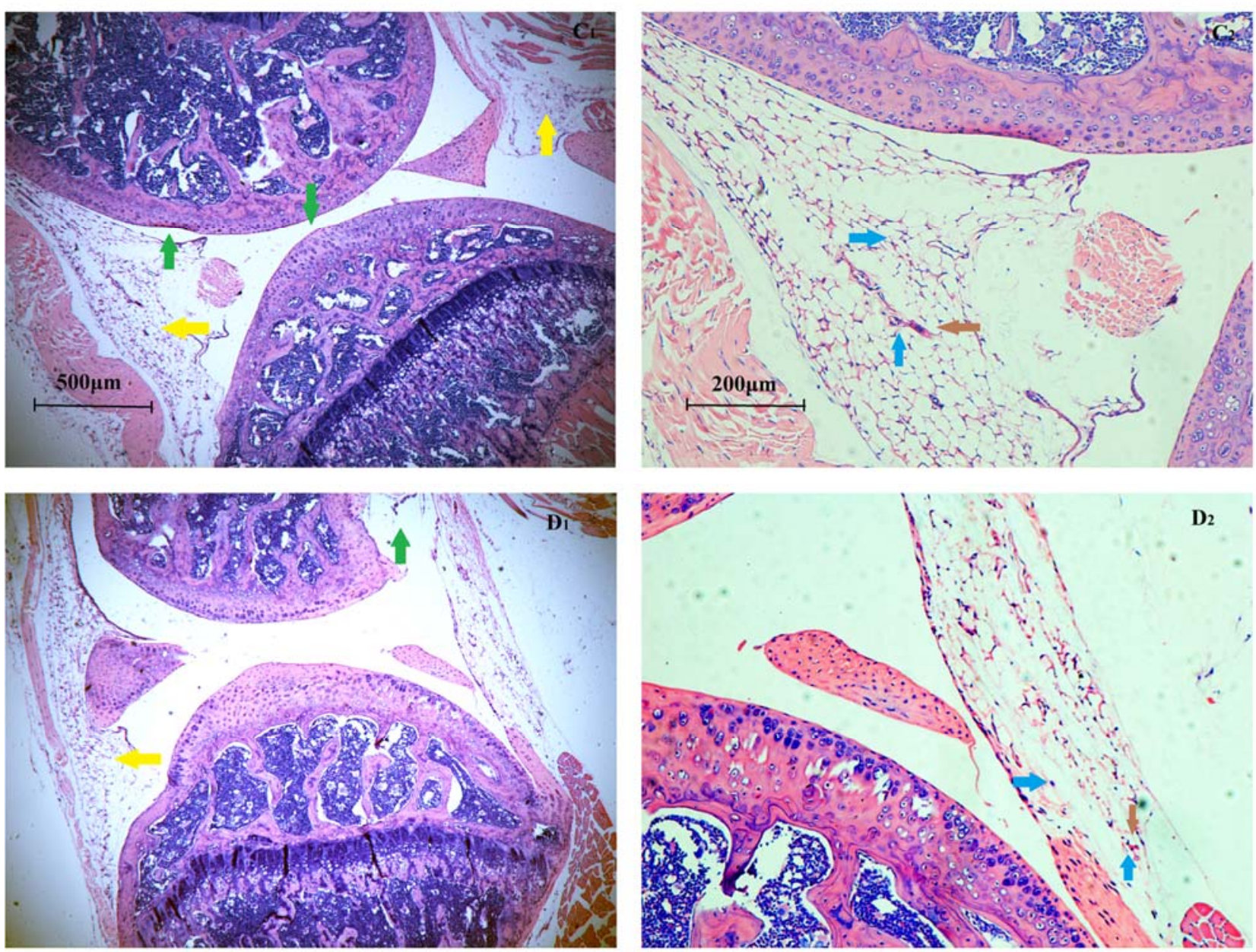

Fig.4. Histology changes of joints from the the Dex and TGs treated mice: (C) $3 \mathrm{mg} / \mathrm{kg}$ Dex treated mice; (D) $60 \mathrm{mg} / \mathrm{kg}$ TGs treated mice; Both groups showed mild histology changes of arthritis and open joint space; $\longrightarrow$, cartilage hyperplasy and erosion; $\rightarrow$, synovia hyperplasia; $\rightarrow$, inflammatory cell infiltration; $\rightarrow$, pannus formation. 

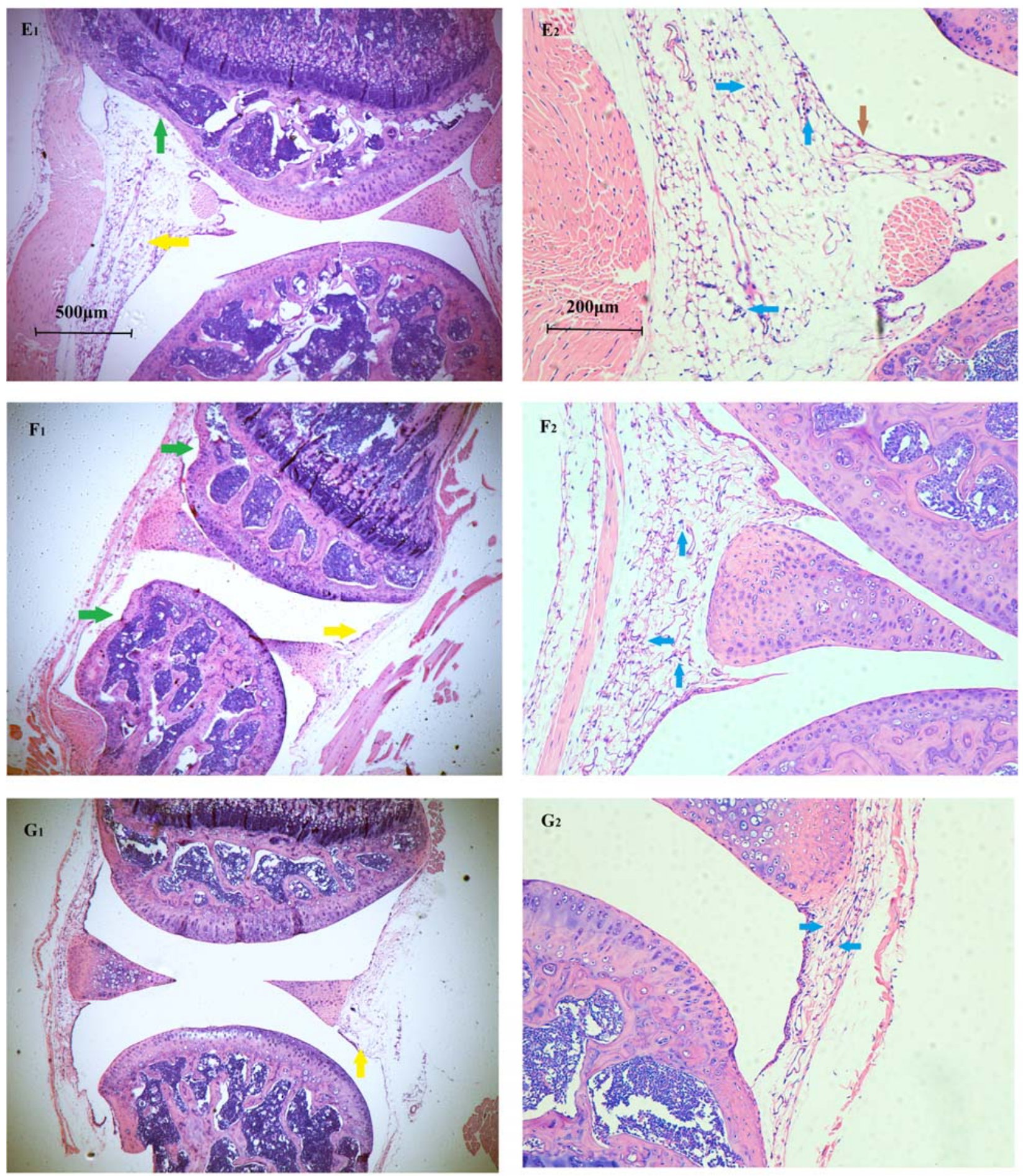

Fig.5. Histology changes of joints from EA treated mice: (E) $140 \mathrm{mg} / \mathrm{kg}$ treated mice. (F) $321 \mathrm{mg} / \mathrm{kg}$ EA treated mice. (G) $936 \mathrm{mg} / \mathrm{kg}$ treated mice. From figure $\mathrm{E}$ to $\mathrm{G}$ showed that EA could decrease the histology changes on collegen induced arthritis in a dose dependent manner. $\rightarrow$, cartilage hyperplasy and erosion; $\rightarrow$, synovia hyperplasia; $\Rightarrow$, inflammatory cell infiltration; $\rightarrow$, pannus formation. 

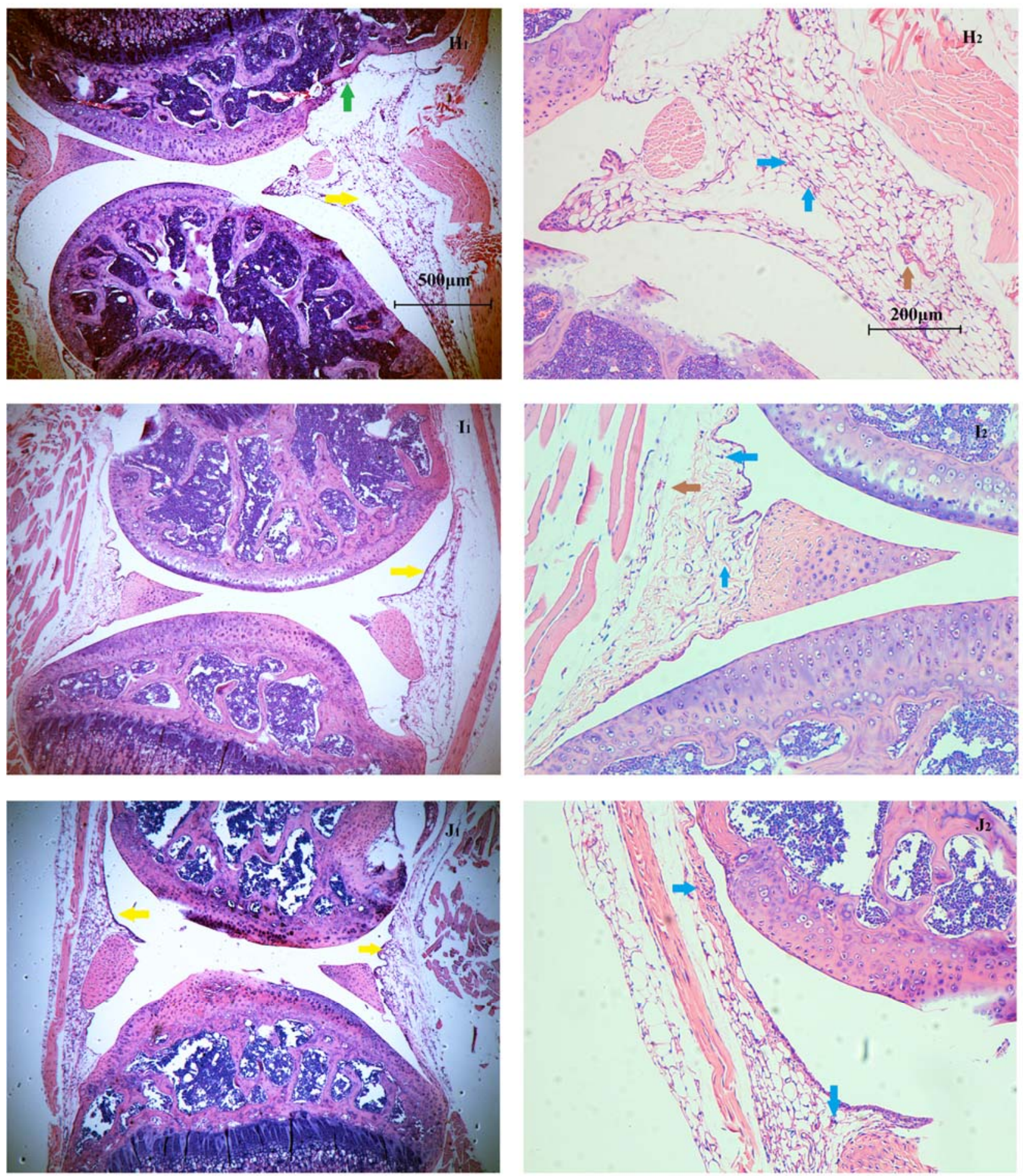

Fig.6. Histology changes of joints from Bu treated mice: (H) $156 \mathrm{mg} / \mathrm{kg}$ Bu treated mice. (I) $469 \mathrm{mg} / \mathrm{kg}$ Bu treated mice. (J) $1407 \mathrm{mg} / \mathrm{kg}$ Bu treated mice. From figure $\mathrm{H}$ to J showed that Bu could decrease the histology changes on collegen induced arthritis in a dose dependent manner. $\rightarrow$, cartilage hyperplasy and erosion; $\rightarrow$, synovia hyperplasia; $\rightarrow$, inflammatory cell infiltration; $\rightarrow$, pannus formation.

3.3. Effect on serum level of TNF- $\alpha$, IL-10, IL- 6 and IL-1 $\beta$

To explore the possible antirheumatic mechanism of both EA and $\mathrm{Bu}$ fractions, blood samples were collected immediately after cervical dislocation. The levels of TNF- $\alpha$, IL-10, IL6 and IL- $1 \beta$ in serum were analyzed by ELISA.

The results (see Fig.7A, 7C, 7D) demonstrated that the serum level of TNF- $\alpha$, IL-6 and IL- 
$1 \beta$ remarkably increased in the CIA model mice (all $P<0.01$ ). Compared with CIA mice, the TNF- $\alpha$, IL- 6 and IL-1 $\beta$ levels in mice treated with either EA $(312,936 \mathrm{mg} / \mathrm{kg})$ or Bu $(469$, $1407 \mathrm{mg} / \mathrm{kg}$ ) fraction were significantly decreased (all $P<0.01)$. EA $(104 \mathrm{mg} / \mathrm{kg}$ ) fraction also reduced the TNF- $\alpha$ level effectively $(P<0.01)$. The serum level of IL-6 was decreased in mice treated with low dose of EA $(104 \mathrm{mg} / \mathrm{kg})(P<0.01)$ and $\mathrm{Bu}(156 \mathrm{mg} / \mathrm{kg})(P<0.01)$ fractions. As shown in Fig.7B, the serum level of IL-10 in CIA mice was sharply decreased $(P<0.01)$. The IL-10 level of mice treated with EA $(312,936 \mathrm{mg} / \mathrm{kg})$ and Bu $(469,1407 \mathrm{mg} / \mathrm{kg})$ fractions was clearly increased compared with the model group (all $P<0.01$ ). All dosages of EA (104, $312,936 \mathrm{mg} / \mathrm{kg}$ ) fraction showed an effect on serum TNF- $\alpha$ and IL-6 levels. Similarly, all dosages of $\mathrm{Bu}(156,469,1407 \mathrm{mg} / \mathrm{kg})$ fraction showed an effect on serum IL-10 and IL-6 levels.

These results demonstrate that the pathway of cytokine synthesis may be involved in the antirheumatic effect of both EA and Bu fractions of SGD extract. 

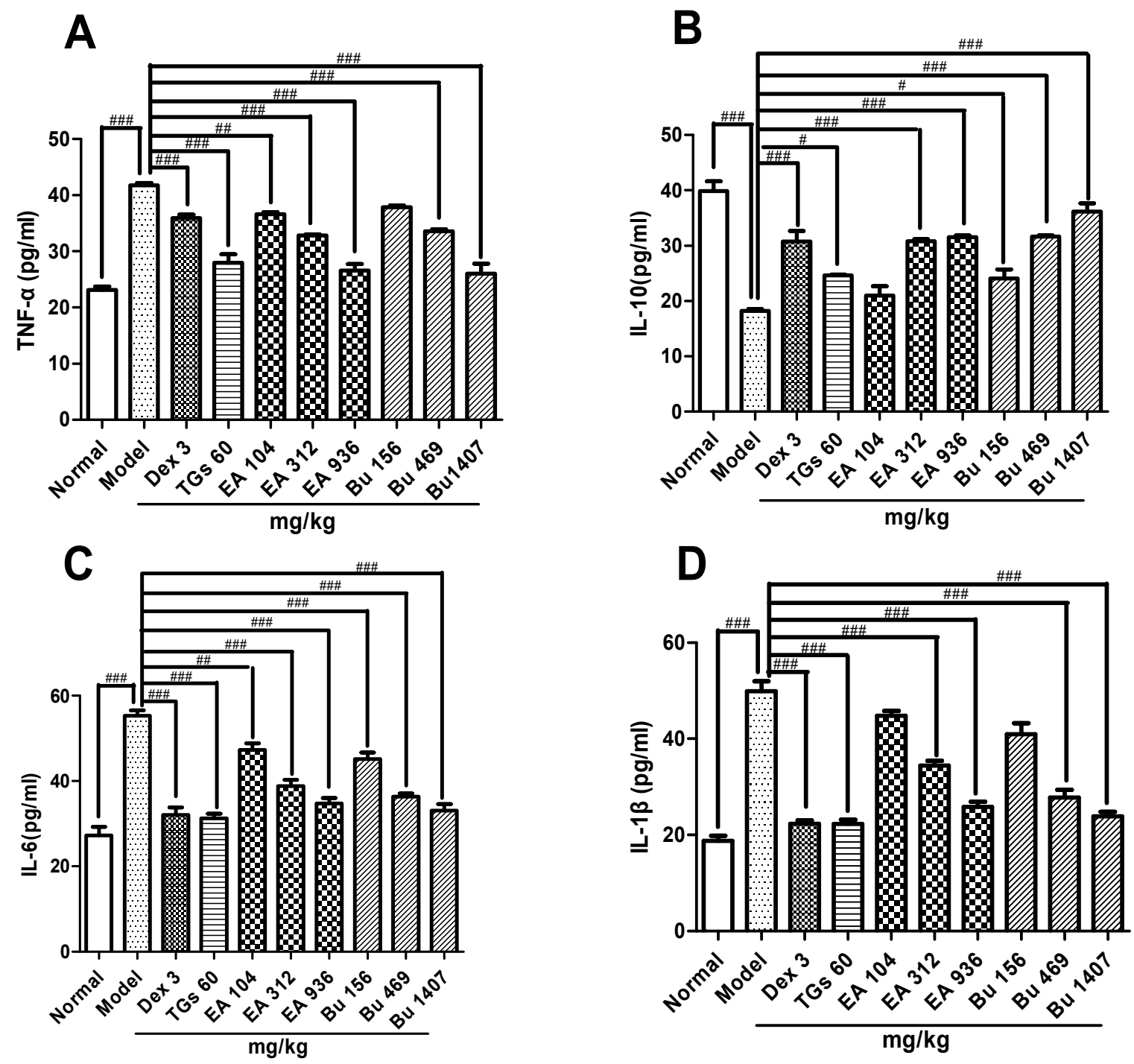

Fig.7. Levels of serum TNF- $\alpha$, IL-10, IL-6 and IL-1 $\beta$ in mice (mean \pm SEM., $\mathrm{n}=10$ ). Data were analyzed by one-way ANOVA followed by Tukey's post hoc analysis. Values represent mean $\pm \operatorname{SEM}(n=10), \# P<0.05, \# \# P<0.01$, \#\#\# $P<$ 0.005 compared with the model group.

\section{Discussion}

Rheumatoid arthritis (RA) is an autoimmune and chronic inflammatory disorder that primarily targets the synovial membrane, cartilage and bone. CIA is an established experimental model of polyarthritis with many histopathological features similar to RA (Di Paola and Cuzzocrea, 2008) and thus extensively used to study the disease pathogenesis and potential therapies. As a traditional folk medicine, Schisandra glaucescens Diels (SGD) has been long used to treat rheumatic arthritis in Enshi, Hubei, China. Our study demonstrated that EA and $\mathrm{Bu}$ fractions of SGD had an obvious therapeutic effect on CIA mice with extremely low toxicity. 
In the present study, both $\mathrm{EA}$ and $\mathrm{Bu}$ fractions showed extremely low toxicity. After treatment with the highest dose that can be suspended in CMC-Na $(200 \mathrm{~g} / \mathrm{kg}$ body weight, equivalent to the dry stems), no mice died or showed any abnormal behaviors or body-weight loss. As a result, the treatment doses of EA and $\mathrm{Bu}$ fractions are much lower than the half lethal dose. This study also indicated that SGD is a safe herbal medicine for treating RA.

We have demonstrated that the oral administration of both the EA and Bu fraction of SGD extract effectively and dose-dependently suppress the paw edema in Balb/c mice. The spleen is an important immune organ in the body. Since RA is induced by auto-immune regulative disorders, the spleen is supposed to be influenced in the process of RA. In our study, $\mathrm{Bu}$ and EA fractions effectively reduced the spleen index of CIA mice, especially EA at the dose of $936 \mathrm{mg} / \mathrm{kg}$ and all doses of $\mathrm{Bu}$ fraction. From the histopathological point, EA and Bu fractions visibly inhibited synovial hyperplasia, inflammatory cell infiltration, pannus formation and cartilage erosion.

This study indicates that SGD inhibits arthritis via a variety of ways. EA and Bu fractions decreased the serum levels of TNF- $\alpha$, IL-6 and IL-1 $\beta$ and increased the level of IL-10. As a proinflammatory cytokine, TNF- $\alpha$ plays a special role in the regulation of other equally strong proinflammatory cytokines e.g. IL-1, IL-6, IL-8 and granulocyte-macrophage colonystimulating factors (Brand et al., 2007; Feldmann et al., 1996). With the assistance of the

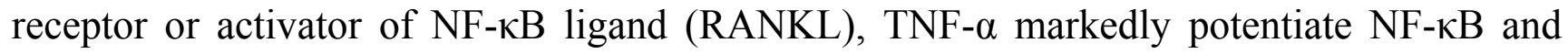
stress-activated protein kinase/c-Jun $\mathrm{NH}_{2}$-terminal kinase activity, two signaling pathways essential for osteoclastogenesis (Lam et al., 2000). The efficacy of anti-TNF- $\alpha$ agents such as infliximab and etanercept in the treatment of RA has been demonstrated in large-scale trials (Lipsky et al., 2000; Maini et al., 1999; Moreland et al., 1999). IL-1 $\beta$ is the key mediator with regard to cartilage and bone destruction. Blockage of IL-1, either after onset or during established CIA, effectively suppresses the arthritic process (Joosten et al., 1999). In the acute phase of RA, IL- 6 obviously increases and its increase positively relates to the damage of joints. Meanwhile, IL-10 has been regarded as upstream regulators that control the progression of RA negatively (Apparailly et al., 1998). The various functions of IL-10 include downregulation of co-stimulatory molecules and the class II MHC molecule, prevention of inflammatory mediator secretion, inhibition of cytokine secretion from $\mathrm{T}$ cells, induction of anergy of T cells, and promotion of the differentiation and survival of B cells (de Waal et al., 1991; Groux et al., 1998). IL-10 not only inhibit the biosynthesis of cytokines produced by 
Th1 cells, such as IFN- $\gamma$, TNF- $\alpha$, IL-1 and GM-CSF, but also inhibit IL-18 mRNA expression (Marshall et al., 1999). The therapeutic effect of SGD appears to be related to its modulation of the key cytokines in RA pathogenesis, including decreasing the levels of TNF- $\alpha$, IL-6, IL$1 \beta$ and increasing the level of IL-10 in the serum of CIA mice. In the present study, the level of IL-1 $\beta$ was significantly decreased in the serum of CIA mice after the oral administration of $\mathrm{EA}(312,936 \mathrm{mg} / \mathrm{kg})$ or $\mathrm{Bu}(469,1407 \mathrm{mg} / \mathrm{kg})$ fraction. The drawdown of IL- $1 \beta$ is caused not only by the direct effect of SGD, but also by the decreased TNF- $\alpha$ and increased IL-10. Consequently, modulating the key cytokines in RA process was speculated to be one of the anti-RA mechanisms of SGD.

In conclusion, EA and Bu fractions of SGD had an obvious therapeutic effect on CIA mice with extremely low toxicity. It is deserve to further screen the active compounds in SGD extract, and to explore the exact mechanism of the anti-arthritis activity.

\section{Acknowledgements}

This project was financially supported by the National Natural Science Foundation ( No.31000150 to J.F. and 30901395 to X.T.) and the Fundamental Research Funds for the Central Universities, HUST ( No. 2012QN006 and 2014QN125).

\section{Appendix A. Abbreviations}

$\mathrm{Bu} \quad$ Fractions extracted by n-butyl alcohol

CIA collagen-induced arthritis

CII type II bovine collagen

Dex dexamethasone

EA Fractions extracted by ethylacetate

ELISA enzyme-linked immunesorbent assay kit

IL-1 $\beta \quad$ interleukin 1 beta

IL-6 interleukin 6

IL-10 interleukin 10

RA rheumatoid arthritis

RANKL receptor or activator of NF-KB ligand

SGD Schisandraglaucescens Diels

TGs Tripterygium Glycosides 


\section{References:}

Apparailly, F, Verwaerde, C, Jacquet, C, Auriault, C, Sany, J. and Jorgensen, C. 1998. Adenovirus-mediated transfer of viral IL-10 gene inhibits murine collagen-induced arthritis. Journal Of Immunology 160, 5213-5220.

Brand, D.D., Latham, K.A. and Rosloniec, E.F., 2007. Collagen-induced arthritis. Nat Protoc 2, 1269-1275.

Cao X, Jiang J, Zhang S, Zhu L, Zou J, Diao Y, Xiao W, Shan L, Sun H, Zhang W, Huang J, Li H. 2013. Discovery of natural estrogen receptor modulators with structure-based virtual screening. Bioorg Med Chem Lett 23, 3329-33.

Chen, C.X., Zh, P., P, H.F., R, H.L., H, Z.H. and W, J.Z., 2011. Extracts of Arisaema rhizomatum C.E.C. Fischer attenuate inflammatory response on collagen-induced arthritis in BALB/c mice. Journal Of Ethnopharmacology 133, 573-582.

China Flora Editing Group, 1996. Flora Republicae Popularis Sinicae. Science Press 30, 258. Chinese Materia Medica Editorial Board, 1999. Chinese Materia Medica, fourth ed. Shanghai Science and Technology Press, Shanghai, pp.2911-2912.

de Waal, M.R., Abrams, J., Bennett, B., Figdor, C.G. and de Vries, J.E., 1991. Interleukin 10(IL-10) inhibits cytokine synthesis by human monocytes: an autoregulatory role of IL10 produced by monocytes. Journal Of Experimental Medicine 174, 1209-1220.

Di Paola, R. and Cuzzocrea, S., 2008. Predictivity and sensitivity of animal models of arthritis. Autoimmun Rev 8, 73-75.

Earp, J.C., Pyszczynski, N.A., Molano, D.S. and Jusko, W.J., 2008. Pharmacokinetics of dexamethasone in a rat model of rheumatoid arthritis. Biopharmaceutics \& Drug Disposition 29, 366-372.

Feldmann, M., Brennan, F.M. and Maini, R.N., 1996. Role of cytokines in rheumatoid arthritis. Annual Review Of Immunology 14, 397-440.

Firestein, G.S., 2003. Evolving concepts of rheumatoid arthritis. Nature 423, 356-361.

Fu, S.X., 1976. Flora Hubeiensis. Hubei Scientific and Technological Press 1, 438.

Groux, H., Bigler, M., de Vries, J.E. and Roncarolo, M.G., 1998. Inhibitory and stimulatory effects of IL-10 on human CD8+ T cells. Journal Of Immunology 160, 3188-3193.

Hueber, A.J. and McInnes, I.B., 2007. Immune regulation in psoriasis and psoriatic arthritis-recent developments. Immunology Letters 114, 59-65.

Joosten, L.A., Helsen, M.M., Saxne, T., van De Loo, F.A., Heinegard, D. and van Den Berg, W.B., 1999. IL-1 alpha beta blockade prevents cartilage and bone destruction in murine type II collagen-induced arthritis, whereas TNF-alpha blockade only ameliorates joint inflammation. Journal Of Immunology 163, 5049-5055.

Jung, H.W., Jung, J.K., Son, K.H., Lee, D.H., Kang, T.M., Kim, Y.S. and Park, Y.K., 2012. Inhibitory effects of the root extract of Dipsacus asperoides C.Y. Cheng et al T.M.Ai on collagen-induced arthritis in mice. Journal Of Ethnopharmacology 139, 98-103.

Kang, I., Lee, W.W. and Lee, Y., 2000. Modulation of collagen-induced arthritis by IL-4 and dexamethasone: the synergistic effect of IL-4 and dexamethasone on the resolution of CIA. Immunopharmacology 49, 317-324.

Lam, J., Takeshita, S., Barker, J.E., Kanagawa, O., Ross, F.P. and Teitelbaum, S.L., 2000. 
TNF-alpha induces osteoclastogenesis by direct stimulation of macrophages exposed to permissive levels of RANK ligand. Journal Of Clinical Investigation 106, 1481-1488.

Lipsky, P.E., van der Heijde, D.M., St, C.E., Furst, D.E., Breedveld, F.C., Kalden, J.R.,

Smolen, J.S., Weisman, M., Emery, P., Feldmann, M., Harriman, G.R. and Maini, R.N., 2000. Infliximab and methotrexate in the treatment of rheumatoid arthritis. Anti-Tumor

Necrosis Factor Trial in Rheumatoid Arthritis with Concomitant Therapy Study Group.

N Engl J Med 343, 1594-1602.

Liu, D.Y., Zhao, H.M., Cheng, S.M., Rao, Y., Huang, X.Y., Zuo, Z.Q., Lei, M., Guan, Y.M., Liu, H.N. and Lu, A.P., 2012. Scorpio and Scolopendra attenuate inflammation and articular damage in rats with collagen-induced arthritis. Journal Of Ethnopharmacology 141, 603-607.

Maini, R., St, C.E., Breedveld, F., Furst, D., Kalden, J., Weisman, M., Smolen, J., Emery, P., Harriman, G., Feldmann, M. and Lipsky, P., 1999. Infliximab (chimeric anti-tumour necrosis factor alpha monoclonal antibody) versus placebo in rheumatoid arthritis patients receiving concomitant methotrexate: a randomised phase III trial. ATTRACT Study Group. Lancet 354, 1932-1939.

Marshall, J.D., Aste-Amezaga, M., Chehimi, S.S., Murphy, M., Olsen, H. and Trinchieri, G., 1999. Regulation of human IL-18 mRNA expression. Clinical Immunology 90, 15-21.

Moreland, L.W., Schiff, M.H., Baumgartner, S.W., Tindall, E.A., Fleischmann, R.M., Bulpitt, K.J., Weaver, A.L., Keystone, E.C., Furst, D.E., Mease, P.J., Ruderman, E.M., Horwitz, D.A., Arkfeld, D.G., Garrison, L., Burge, D.J., Blosch, C.M., Lange, M.L., McDonnell, N.D. and Weinblatt, M.E., 1999. Etanercept therapy in rheumatoid arthritis. A randomized, controlled trial. Annals Of Internal Medicine 130, 478-486.

Myers, L.K., Rosloniec, E.F., Cremer, M.A. and Kang, A.H., 1997. Collagen-induced arthritis, an animal model of autoimmunity. Life Sciences 61, 1861-1878.

Rosloniec, E.F., Cremer, M., Kang, A.H., Myers, L.K. and Brand, D.D., 2010. Collageninduced arthritis. Curr Protoc Immunol Chapter 15, 15.

Seeuws, S., Jacques, P., Van Praet, J., Drennan, M., Coudenys, J., Decruy, T., Deschepper, E., Lepescheux, L., Pujuguet, P., Oste, L., Vandeghinste, N., Brys, R., Verbruggen, G. and Elewaut, D., 2010. A multiparameter approach to monitor disease activity in collageninduced arthritis. Arthritis Res Ther 12, R160.

Shaw, S.R., Nihal, M. and Ahmad N., 2008. Dose translation from animal to human studies revisited. The Journal of the Federation of American Societies for Experimental Biology 22, 659-661.

Silverstein, F.E., Faich, G., Goldstein, J.L., Simon, L.S., Pincus, T., Whelton, A., Makuch, R., Eisen, G., Agrawal, N.M., Stenson, W.F., Burr, A.M., Zhao, W.W., Kent, J.D., Lefkowith, J.B., Verburg, K.M. and Geis, G.S., 2000. Gastrointestinal toxicity with celecoxib vs nonsteroidal anti-inflammatory drugs for osteoarthritis and rheumatoid arthritis: the CLASS study: A randomized controlled trial. Celecoxib Long-term Arthritis Safety Study. JAMA 284, 1247-1255.

Simon, L.S., 2000. DMARDs in the treatment of rheumatoid arthritis: current agents and future developments. International Journal Of Clinical Practice 54, 243-249.

Smolen, J.S. and Steiner, G., 2003. Therapeutic strategies for rheumatoid arthritis. Nature Reviews Drug Discovery 2, 473-488.

Walum, E., 1998. Acute oral toxicity. Environ Health Perspect 106, 497-503.

Wan, D.R., Wang, L.R., Li, A.J., Qian, C., 1990. Common-used Tujia herb drugs for traumatic injury in Hubei Province. Zhongyaocai 13, 16-18. (in Chinese). 
Wan, L., Liu, J., Huang, C.B., Wang, Y., Lei, L., Liu, L., Cheng, Y.Y. and Feng, Y.X., 2013. Effect of tripterygium glycosides on pulmonary function in adjuvant arthritis rats. J Chin Med Assoc 76, 715-723.

Xiong, C.J., Wu G.H., Li, Y., Zeng, D.L., Wang, Y.G., Cheng, J.G., Xie, H., Zhang, H.L., 2004. Varieties research of Miao drugs "Xueteng" of Schisandraceae. Journal of Medicine \& Pharmacy of Chinese Minorities S1, 140-145. (in Chinese).

Yu HY, Chen ZY, Sun B, Liu J, Meng FY, Liu Y, Tian T, Jin A, Ruan HL. 2014. Lignans from the fruit of Schisandra glaucescens with antioxidant and neuroprotective properties. J Nat Prod 77, 1311-20.

Yu HY, Hao C, Meng FY, Li X, Chen ZY, Liang X, Ruan HL. 2012. Neuroprotective lignans from the stems of Schisandra glaucescens. Planta Med 78, 1962-1966.

Zhang, L.L.,Wei, W.,Yan, S.X.,Hu, X.Y.,Sun, W.Y., 2004. Therapeuticeffectsof glucosides of Cheanomeles speciosa on collagen-inducedarthritisinmice.Acta Pharmacologica Sinica $25,1495-1501$.

Zou J, Jiang J, Diao YY, Yang LB, Huang J, Li HL, Du X, Xiao WL, Pu JX, Sun HD. 2012. Cycloartane triterpenoids from the stems of Schisandra glaucescens and their bioactivity. Fitoterapia 83, 926-931.

Figure legend 
Fig.1. Chart for experimental design

Fig.2. Effects of SGD on the spleen indexes on CIA mice. Data were analyzed by one-way ANOVA followed by Tukey's post hoc analysis. Values represent mean $\pm \operatorname{SEM}(\mathrm{n}=10)$, \# $P<0.05$, \#\# $P<0.01$ compared with the model group. Model male Balb/c mice only received $0.5 \% \mathrm{CMC}-\mathrm{Na}$ orally.

Fig.3. Histology changes of joints from the normal group and the model group mice: (A) Normal group mice showed the normal articular cartilage, absence of damage in the synovium and open joint space; (B) Model group mice showed marked infiltration of inflammatory cells and synovial hyperplasia. $\longrightarrow$, cartilage hyperplasy and erosion; $\rightarrow$, synovia hyperplasia; $\rightarrow$, inflammatory cell infiltration; $\rightarrow$, pannus formation.

Fig.4. Histology changes of joints from the the Dex and TGs treated mice: (C) 3mg/kg Dex treated mice; (D) $60 \mathrm{mg} / \mathrm{kg}$ TGs treated mice; Both groups showed mild histology changes of arthritis and open joint space; $\rightarrow$, cartilage hyperplasy and erosion; $\rightarrow$, synovia hyperplasia; $\Rightarrow$, inflammatory cell infiltration; $\Rightarrow$, pannus formation.

Fig.5. Histology changes of joints from EA treated mice: (E) $140 \mathrm{mg} / \mathrm{kg}$ treated mice. (F) $321 \mathrm{mg} / \mathrm{kg}$ EA treated mice. (G) $936 \mathrm{mg} / \mathrm{kg}$ treated mice. From figure $\mathrm{E}$ to $\mathrm{G}$ showed that EA could decrease the histology changes on collegen induced arthritis in a dose dependent manner. $\rightarrow$, cartilage hyperplasy and erosion; $\rightarrow$, synovia hyperplasia; $\rightarrow$, inflammatory cell infiltration; $\rightarrow$, pannus formation.

Fig.6. Histology changes of joints from Bu treated mice: (H) $156 \mathrm{mg} / \mathrm{kg} \mathrm{Bu}$ treated mice. (I) $469 \mathrm{mg} / \mathrm{kg}$ Bu treated mice. (J) $1407 \mathrm{mg} / \mathrm{kg} \mathrm{Bu}$ treated mice. From figure $\mathrm{H}$ to $\mathrm{J}$ showed that $\mathrm{Bu}$ could decrease the histology changes on collegen induced arthritis in a dose dependent manner. $\longrightarrow$, cartilage hyperplasy and erosion; $\rightarrow$, synovia hyperplasia; $\rightarrow$, inflammatory cell infiltration; $\rightarrow$, pannus formation.

Fig.7. Levels of serum TNF- $\alpha$, IL-10, IL-6 and IL-1 $\beta$ in mice (mean \pm SEM., $n=10$ ). Data were analyzed by one-way ANOVA followed by Tukey's post hoc analysis. Values represent mean $\pm \operatorname{SEM}(\mathrm{n}=10)$, \# $P<0.05$, \#\# $P<0.01$, \#\#\# $P<$ 0.005 compared with the model group. 